\title{
Exploring Grade 7 Science Teachers' Perceptions Regarding Practical Work in Limpopo, South Africa
}

\author{
Israel Kibirige \\ Joseph Osodo \\ Albert Ndabeni Mgiba \\ University of Limpopo, Polokwane, South Africa \\ Email: Israel.Kibirige@ul.ac.za
}

\section{Doi:10.5901/mjss.2014.v5n4p399}

\begin{abstract}
The purpose of this study was to explore grade 7 Natural Science teachers' perceptions regarding the role of practical work and match them with available evidence from teachers' portfolios. The sample comprised 10 Grade 7 Natural Science teachers, randomly sampled from 27 schools. Questionnaires and teachers' portfolios were used to collect data. The results show that while teachers' perceptions regarding the purpose of practical work in Science is adequate; their perceptions regarding its application in science classrooms is inadequate. Hence, there was a mismatch between teachers' perceptions and what was taking place in the science classroom. The study may inform educational practitioners, policy makers and researchers on ways of improving teaching methods and performance of learners in science. It is recommended that assessment of practical work should be given attention, as most of the teachers do not record marks regularly for practical work.
\end{abstract}

Keywords: Science, teachers' perceptions, practical work

\section{Introduction}

Practical work is an integral part of science education and various science educationists have evaluated its purposes (Toplis \& Allen, 2012). According to Gee and Clackson (1992), the history of practical work in science education suggests that practical work first became a part of Science education in secondary schools in the mid-1850s. Gee and Clackson's observation is further corroborated by Gott and Duggan (1996: 791) who state:

"...By the turn of the century and with the adventure of Armstrong's heurism (1896), practical work was seen as a means of allowing pupils to find out things for themselves. By the 1950s and 1960s, small group practical (SGP) work was believed to be useful in developing reasoning skills, encouraging observation and providing direct contact with the physical world...."

Abrahams and Millar (2008), concur with Hodson (1992) that the motivation for introducing practical work in the mid-nineteenth century was that it would teach students "how to learn". Practical work, hence, provides a basis for the comparison, testing, and development of experiences in science (Lawson, 2010). Kasanda et al. (2003: 134), argues for practical work in the learner-centred Outcomes Based Education (OBE) curriculum and states: "...learner-centred teaching requires that students be offered the opportunity to carry out research rather than depending on the teacher to provide such information...". Baquete (2003) too contends that a learner should develop capacity to transform knowledge into abilities and skills of knowing how to apply them, either in the classroom or in everyday life. Johnstone and Wham (1982), as well as Toplis and Allen (2012), submit that practical work reaches its highest peak when done by pupils themselves rather than by demonstration because pupils engage in discovery learning.

Practical work can be referred to as active learning with the responsibility of organizing what is to be learned (Tafa, 2012; Shakhashiri, 2009; Dodge, 1996). Active learning can therefore involve analysis, synthesis, and evaluation (Choi et al., 2013; Schuster et. al., 2012). Science education is based on observation, investigation and experimentation in order to understand the world (Miller, 2004). Miller (2004) adds that learning science involves practical work which enables learners to have hands-on experience to help them make informed decisions. Braud and Driver (2002) further argue that practical work makes learners get excited and yearn to learn more. The purpose of practical work is to illustrate concepts 
so that learners can "see" science concepts (Gott \& Mashiter, 1991). The Curriculum Assessment Policy Statement (CAPS) in South Africa has specific aims relating to gathering knowledge through practical work (Department of Education Policy document, 2011). Despite these aims, it seems teachers do not explain the aims of activities to learners (Kapenda et al., 2000). Hodson (1992) also contends that the way practical work is conducted in many schools is illconceived and often results in little understanding of what goes on in the laboratory. Maboyi and Dekkers (2003) concur with Hodson that students learn well if they know the purpose and significance of practical work. This implies that every practical work must be designed with a specific purpose.

Gott and Duggan (1996) focus on three key areas: motivational aspects linked to the promotion of interest and observation skills; the application of prior knowledge; and the development of experimental skills. In addition, Berg and Giddings (1992) distinguished the following categories relating to practical skills: affective, practical, and cognitive aims. Affective aims are related to motivating students and influencing their attitude towards experimentation. Practical aims are related to the development of skills like performing investigations, communication and cooperation among learners (D'Avanzo, 2013). Cognitive aims include the development of conceptual understanding and inference skills. Hodson (1996) further describes three major aspects of practical science education as learning science, learning about science and doing science. These aspects encompass the aims of carrying out practical work that include: encouraging accurate observation; careful recording; promoting scientific critical thought; developing manipulative skills and elucidating theoretical work to aid comprehension. Johnstone and Wham (1982) show that laboratory work often overloads students. This is further substantiated by Hodson (1992) when he points out that practical work is at times over-used when teachers expect learners to attain all learning goals. Conversely, practical work is often under-used in the sense that its real potential is rarely fully exploited (Ergin et al., 2005). To strike a balance between under-use and over-use becomes the science teachers' dilemma.

Teachers' perceptions regarding practical work in the teaching of Natural Science are important (Maharaj et al., 2007) as such perceptions determine their actions in science classrooms. Perceptions are defined as a process by which individuals select, organize and interpret stimuli into meaningful and coherent pictures of the world around them (Klazky 1984). Thus, teachers' perceptions are invaluable in the teaching and learning process. This study adopted Klazky's definition of perception as the processes that occur when teachers determine the meaning of what is sensed or stimuli in their classroom environment (Klazky 1984; Woolfolk 1998). Therefore, the focus was on teachers' perceptions regarding practical work in the science classroom and evidence from their records of work (portfolios) to support their subsequent actions. Despite the awareness of the importance of practical work, teachers often do not keep records of learners' performance in practical work, especially, for promotion of learners to the next class. Teachers who fail to include practical work in their teaching schedules cite a number of conditions: lack of laboratory space, inadequate equipment and lack of funds. Some teachers complain about the lack of skills to use laboratory equipment, whilst others claim that they lack adequate time for practical work. These complaints do not remove the role practical work plays in learning science. The role of laboratory work in biology has been previously investigated and teachers agree that practical work is important (Dikmenli, 2009). In biology, teachers focus on the connection between learners' theoretical knowledge and practice. Very little attention is given to the development of scientific process skills and this could be due to teachers' perceptions regarding the purpose of practical work. With little known regarding teachers' perceptions about practical work (Reid \& Shah, 2007), the purpose of the study was to explore teachers' perceptions of practical work in Grade 7 Natural Sciences from Lobethal circuit, Limpopo, South Africa.

\section{Research Questions}

This study was guided by the following research questions:

- What are the perceptions of teachers regarding the purpose of practical work in teaching science?

- To what extent do science teachers engage grade 7 learners in practical work?

\section{Research Design}

A qualitative approach using phenomenological research design was applied. Brynard and Henekom (1997: 30) state that "...qualitative methodologies allow the researcher to know people personally and to see them as they are, as well as to experience their daily struggles when confronted with real-life phenomenal...". In this case the phenomenon is the teachers' perceptions regarding practical work in science classroom. 


\section{Population and Sample}

Of twenty-seven Natural Sciences teachers from Lobethal circuit, Limpopo, ten (5 males and 5 females) were purposively selected based on their experiences which ranged between 5 and 10 years. This range was deemed adequate to provide rich and varied responses relevant to the study (Cresswell, 2007).

\section{Instruments}

The researcher used two instruments: interviews and teachers' portfolios. Interviews comprised of six closed-ended questions. The questions were checked by experts to ascertain validity and necessary amendments were made to the questions according to their recommendations. Also, a pilot study was conducted on four teachers (2 males and 2 females). Ambiguous questions were either removed or amended to increase reliability of the final version. In order to get the perceptions of the science teachers, each of the closed-ended questions was provided with possible answers for the respondents to choose from. Furthermore, the researcher gathered additional information from both teachers' and learners' portfolios in order to corroborate teachers' responses to the questionnaire.

\section{Data Collection}

\subsection{Semi-structured interviews}

The researchers requested each teacher to respond to the interview questions and their answers were written down on a piece of paper. After that, all statements were read by the researcher to ascertain that statements were correctly captured.

\subsection{Teachers' Portfolios}

The researcher examined all the ten teachers' portfolios for evidence of the following components: inclusion of practical work in the work schedule (Scheme of work): lesson plans reflecting practical work; and assessment records for practical work.

\section{Data Analysis}

\subsection{Questionnaires}

The results of the questionnaires were analysed using the percentages of participants that 'agreed or disagreed' in each of the six questions. The responses were sorted out per question showing correct choice. The percentage of acceptable choice from teachers was computed by taking correct choices of each question over the total number of teachers.

Acceptable $\%=\frac{\text { correct choices }}{\text { total possible choices (10) }} \times 100 \%$

Thereafter, responses were read and reread in order to get themes and categories (Rubin \& Rubin, 1995).

\subsection{Teachers' Portfolios}

Data were analysed using a rubric with a scale that ranged from 0 to 3 where $0,1,2,3$ represented none, one, two and three of the components, respectively for all the three components namely: the inclusion of practical work in the work schedule; lesson plans reflecting practical work; and assessment records for practical work. Furthermore, work schedules, number of practical lessons and number of assessments per teacher were compared to themes from the questionnaires.

\section{Results}

The findings show that Grade 7 science teachers had misconceptions regarding the purpose of practical work. These misconceptions are presented as four themes. 
Table 1: Percentage agreement from questions regarding practical work.

\begin{tabular}{|c|c|c|c|c|c|c|}
\hline Respondents & Q 1 & Q 2 & Q 3 & Q 4 & Q 5 & Q 6 \\
\hline 1 & $\mathrm{~B}^{*}$ & $\mathrm{~B}^{*}$ & $\mathrm{C}^{*}$ & $\mathrm{~B}^{*}$ & $\mathrm{~A}$ & $\mathrm{D}^{*}$ \\
\hline 2 & $\mathrm{~B}^{*}$ & $\mathrm{C}$ & $\mathrm{A}$ & $\mathrm{B}^{*}$ & $\mathrm{C}$ & $\mathrm{C}$ \\
\hline 3 & $\mathrm{~B}^{\star}$ & $\mathrm{A}$ & $\mathrm{B}$ & $\mathrm{B}^{*}$ & $\mathrm{~A}$ & $\mathrm{C}$ \\
\hline 4 & $\mathrm{~B}^{*}$ & $\mathrm{~A}$ & $\mathrm{~B}$ & $\mathrm{C}$ & $\mathrm{C}$ & $\mathrm{B}$ \\
\hline 5 & $\mathrm{~A}$ & $\mathrm{~A}$ & $\mathrm{~A}$ & $\mathrm{~A}$ & $\mathrm{~A}$ & $\mathrm{~A}$ \\
\hline 6 & $\mathrm{~B}^{*}$ & $\mathrm{C}$ & $\mathrm{A}$ & $\mathrm{C}$ & $\mathrm{C}$ & $\mathrm{B}$ \\
\hline 7 & $\mathrm{~A}$ & $\mathrm{~A}$ & $\mathrm{~B}$ & $\mathrm{~A}$ & $\mathrm{~B}^{*}$ & $\mathrm{~B}$ \\
\hline 8 & $\mathrm{~B}^{*}$ & $\mathrm{~B}^{*}$ & $\mathrm{C}^{*}$ & $\mathrm{~B}^{*}$ & $\mathrm{~A}$ & $\mathrm{D}$ \\
\hline $\mathrm{A}$ & $\mathrm{A}$ & $\mathrm{A}$ & $\mathrm{B}$ & $\mathrm{C}$ & $\mathrm{C}$ & $\mathrm{B}$ \\
\hline 10 & $\mathrm{C}$ & $\mathrm{A}$ & $\mathrm{A}$ & $\mathrm{C}$ & $\mathrm{B}^{*}$ & $\mathrm{C}$ \\
\hline Acceptable (\%) & 60 & 20 & 20 & 40 & 20 & 20 \\
\hline
\end{tabular}

* Acceptable choice

\subsection{Theme 1: Translating theory into practice}

Sixty percent of the respondents in question 1 recognized (choice B) that the purpose of practical work in science is to involve learners so that they can learn through observation, experimenting, and translating theory into practice, as compared to thirty percent who said that the purpose of practical work in Science is to help learners who are struggling with theory work to cope. Only one in ten (choice $\mathrm{C}$ ) of the respondents said the purpose was to give learners the opportunity to collaborate amongst themselves, and with the teacher, and to save time.

\subsection{Theme 2: Class activity that replaces real practical work}

For question 2 only 20\% (Choice B) accepted that it was possible to engage learners in practical work without a laboratory or laboratory equipment. Another $20 \%$ (Choice C) said learners can only be engaged sporadically in practical work if there is no laboratory or laboratory equipment. This is in contrast to the sixty percent who claimed that it is impossible to engage learners in practical work without a laboratory or laboratory equipment.

\subsection{Theme 3: Practical work should not be included in class performance assessment}

Forty percent (Choice A) felt it was not necessary to include the learners' performance in practical work when deciding to pass or fail them. A similar number (40\%) were convinced that the learners' performance in practical work should be considered only when the learners' performance in theory work was unsatisfactory, otherwise it was not necessary. As in question 2, only $20 \%$ in question 3 said it was necessary to include the learners' performance in practical work when deciding to pass or fail them. In question 4, 40\% (Choice B) of the respondents said that there was need to assess the learners' performance in practical work. A similar $40 \%$ thought they should not always assess the learners' performance in practical work, while only $20 \%$ said it depended on the type of the practical work. Again, four respondents in question 5 (40\%) fittingly understood that learners should be engaged in practical work twice per month, in line with the national assessment guidelines. On the other hand, $40 \%$ felt that learners should not be engaged in practical work at all and this is inconsistent with the sixty percent who acknowledged the appropriate purpose of practical work in question 1. A mere $20 \%$ of the respondents thought learners should be engaged in practical work only once a month.

\subsection{Theme 4: Necessity of planning practical prior class time}

For the last question, question 6, only $20 \%$ (Choice D) conceded that it is important to plan prior to engaging learners in practical work. Of the ten respondents, forty percent claimed that "... if a teacher has many years of teaching experience, planning is not really important...". Twenty percent stated that it was not important to plan for practical work, while ten percent thought that planning for practical work depended on the type of practical work to be set. 


\subsection{Teachers' Portfolios}

Table 2: Rubric scale and percentage results from the teachers' portfolios regarding practical work.

\begin{tabular}{|c|c|c|c|c|}
\hline Respondents & $\begin{array}{c}\text { Evidence of Practical Work in } \\
\text { Work Schedule }\end{array}$ & $\begin{array}{c}\text { Evidence of Practical Work } \\
\text { in Lesson Plans }\end{array}$ & $\begin{array}{c}\text { Evidence of Practical Work in } \\
\text { Assessment Records }\end{array}$ & Scale \\
\hline 1 & $\sqrt{ }$ & $\sqrt{ }$ & $\mathrm{X}$ & 3 \\
\hline 2 & $\sqrt{ }$ & $\sqrt{ }$ & $\mathrm{X}$ & 2 \\
\hline 3 & $\sqrt{ }$ & $\mathrm{X}$ & $\mathrm{X}$ & 1 \\
\hline 4 & $\mathrm{X}$ & $\mathrm{X}$ & $\mathrm{V}$ & 1 \\
\hline 5 & $\sqrt[X]{ }$ & $\mathrm{X}$ & 1 \\
\hline 6 & $\mathrm{X}$ & $\mathrm{X}$ & $\mathrm{X}$ & 0 \\
\hline 7 & $\mathrm{X}$ & $\mathrm{X}$ & $\mathrm{X}$ & 0 \\
\hline 8 & $\mathrm{X}$ & $\mathrm{X}$ & $\mathrm{X}$ & 0 \\
\hline 9 & $\mathrm{X}$ & $\mathrm{X}$ & 20 & 0 \\
\hline 10 & 50 & 30 & & \\
\hline Percentage $(\%)$ & $\mathrm{V}$ & & & \\
\hline
\end{tabular}

Key: 0, 1, 2, 3 represented none, one, two and three of the components

From the portfolios, only one out of 10 respondents had all the 3 expectations of the benchmark tool. This translates to only ten percent of the sample. Two respondents met the expectations of scale 2. This is twenty percent of the sample. In the portfolios of these respondents there were no assessment records for practical work, whilst the rest of the descriptors were evident. Thirty percent of the sample fell into scale 1. Of the three, two had included practical work only in their work schedules. There were no lesson plans or assessment records related to practical work. The last respondent in scale 2 only had assessment records related to practical work. Majority of the respondents, who make forty percent of the sample, fell into scale 0 because these four did not have any evidence related to practical work in their portfolios.

A significant fifty percent of the respondents had evidence of practical work in their work schedules. However, this number is not comparable with the number of teachers assessing the practical work given to learners: only twenty percent had evidence of practical work in their assessment records. This number is slightly lower than the thirty percent of those that included practical work when planning their science lessons.

\section{Discussion}

A large percentage of the sample (sixty percent) responded that they had an adequate understanding of the purpose of practical work in Science. This is demonstrated by their appropriate response to question 1 of the questionnaire, which dealt directly with the purpose of practical work in Science. These six respondents fittingly answered that the purpose of practical work in Science is to involve learners so that they can learn through observation, experimenting, and translating theory into practice, which is in line with Miller (2004) who contends that learning science involves practical work to enable learners to have hands-on experience. Got and Duggan (1996) also viewed practical work to be useful in developing reasoning skills, encouraging observation and providing direct contact with the physical world.

The teachers' perceptions of the purpose of practical work was not translated into practical application, as reflected in the observations into their accompanying responses to broad questions, and the evidence from their portfolios (Table $1 \&$ 2). Twenty percent of the participants responded appropriately in all the six questions from the questionnaire: teachers chose $\mathrm{B}$ for both the first, second, and the fourth questions, $\mathrm{C}$ for the third question, $\mathrm{A}$ for the fifth question, and $\mathrm{D}$ for the last question (Table 1). These respondents reflected the ideal nature of a Science teacher as envisaged by the National Curriculum Statement (NCS). One of the respondents matched the expectations of scale 3 in respect to the portfolios and reflects consistency between the findings in the portfolio and the responses from the questionnaire. On the other hand, the one respondent here matched the expectations of scale 1, which shows inconsistency between the findings in the portfolio and the responses from the questionnaire.

Ten percent of the sample answered question 2 and 3 inappropriately. Only one of the respondents matched the expectations of scale 3 . The respondent's responses were similar to the findings in the respondent's portfolio: while the respondent acknowledges the need to always assess learners' performance in practical work in question 4, the respondent had no assessment records of the learners' performance in practical work. In question 2 the respondent answered that '...it is not feasible to engage learners in practical work without a laboratory and or laboratory 
equipment...', hence no assessment records for practical work in the portfolio, despite the plan in the Work Schedule and the Lesson Planning.

The view of the respondent above is partially misguided, considering that the DoE (2002a: 50) states that "...besides, many investigations can, and should be, carried out with the use of improvised equipment...". Maboyi and Dekkers (2003) suggest that introducing readily available materials found in the kitchen and the dust bin, as an example, can be used effectively in practical work. However, it should be noted that Maboyi and Dekkers (2003) also found that large classes and lack of materials are the main reasons that science teachers give for not conducting practical work. They concluded that schools and teachers need basic requirements such as electricity, water and science equipment like bunsen burner, test-tube, measuring instruments that would allow students to work. The most common problems apparently are lack of infrastructure, laboratory equipment and over-crowding. The unavailability of equipment was a significant issue for most of the teachers. Jacobs (undated) also asserts that there is a lack of science equipment at many of the South African schools.

Again, only ten percent responded appropriately to two of the six questions. These respondents were graded at scale 3 (that practical work should be in work schedule, and should be part of the assessment) in terms of the portfolios. One respondent expectedly answered question 1, which was about the purpose of practical work in Science and also question 4 which was about the need to assess practical work. It seems that whilst this respondent acknowledged the purpose and the need to assess practical work, the respondent did not consider practical work in the final grade of the learners. There were no records of assessment of such practical work in the portfolio. The respondent, therefore, regarded all assessment in practical work as informal and this was corroborated by the respondent's response to question 3 dealing with what to include in the total marks that constitute the pass rate of a learner. This respondent had a narrow view of assessment, as the DoE (2005) states that in Natural Science, the teacher might use practical work or a project or a test to assess whether a learner is able to plan an investigation and the level at which she/he can perform this. The DoE further provides projects, oral presentations, demonstrations, performances, tests, exams, practical demonstrations, as examples of what could be included as formal assessment. However, Kasanda et al. (2003) have concluded that little knowledge and little understanding of assessment instruments by teachers cause problems, while Maboyi and Dekkers (2003) revealed that contextual factors such as over-crowding of classrooms were the major obstacle to carry out assessment.

The DoE (2005: 22) also maintains that "...progression and promotion of learners to the next grade should be based on recorded evidence. This means that those tasks that are used for formal assessment should be recorded and used to decide whether a learner should progress or be promoted to the next grade...". Three respondents, equivalent to thirty percent of the respondents, responded appropriately to only one question. All these three respondents matched the expectations of scale 2. Two of these three respondents appropriately answered question one, which is directly about the purpose of practical work. Of the two, one had assessment records on practical work, and the other had no such a record although practical work was included in the Work Schedule. Their response to question one shows that they had the relevant perception about the purpose of practical work in Science. The third respondent answered question 5, which focused on the number of practical work exercises per month. This respondent's pattern of responses gives the impression that the respondent were guessing, since in all the questions the responses was ' $A$ '. Nothing meaningful can be concluded from this respondent's completion of the questionnaire.

There were three respondents (thirty percent) who answered all the questions of the questionnaire inappropriately. One of these respondents matched the expectations of scale 1 . This is the respondent who had only included practical work in the Work Schedule, with no other evidence in the portfolios. The reason for this could be that the respondent 'inherited' the Work Schedule from a predecessor. This respondent could have had no expertise in the teaching of Science because the Work Schedule was not used at all. This explains why the respondent could not appropriately answer any question from the questionnaire.

The remaining two respondents who responded inappropriately to all the questions matched the expectations of scale 1. This correlation between the findings in their portfolios and their responses from the questionnaire shows consistency, and it could be because the respondents had no knowledge about the teaching of Science. This is contrary to the expectation of the DoE's (2002b: 9), which states that the kind of teachers envisaged in this new dispensation are "...scholars, researchers and lifelong learners...assessors and learning area specialists...".

\section{Conclusion}

The results of this study indicate that some science teachers had misguided perceptions regarding the purpose of 
practical work. While sixty percent of the respondents in this study had adequate understanding of the purpose of practical work in Science teaching but the responses other questions revealed that these teachers had misconceptions about practical work. Another significant discovery of this study is that while most teachers were aware of the need to include practical work in their schedules, the majority of the teachers were reluctant to plan for its teaching and were not prepared to conduct as well as assess practical work. Whereas the teachers' theoretical perceptions regarding the purpose of practical work in science were relatively adequate, their perceptions regarding application were inappropriate. It is, therefore, recommended that assessment of practical work be given more attention than is currently as most of the teachers do not record marks regularly for practical work. Also, a study about practical work and assessment should be undertaken as a means to assess the pervasiveness of the problem.

\section{References}

Abrahams, I. \& Millar, R. (2008). Does practical work really work? A study of the effectiveness of practical work as a teaching and learning method in school science. International Journal of Science Education, 30, 1945-1969.

Berg, E. \& Giddings, G. (1992). An alternative view of laboratory teaching, Curtin University, Bentley, Australia. Monograph.

Baquete, A. (2003). Rethinking the teaching of the Natural Science to meet the demand of the changes in the world for the future generations: the role of the arts and professional training school- APTS in Mozambique, Eduardo Mondlane University. pp. 70. Paper presented at the 11th annual SAARMSTE conference in Waterford Kamhlaba UWC, 2003.

Braud, M. \& Driver, M. (2002). Moving to the big school. What do pupils think about Science practical work pre- and post transfer? In http://www.leeds.ac.uk/educol/documents /00002157. htm. Accessed 29/09/2013.

Brynard, P. A \& Hanekom, S. X. (1997). Introduction to Research in Public Administration. Pretoria : J. L. van Schaik.

Choi, A., Hand, B. \& Greenbowe, T. (2013). Students' Written Arguments in General Chemistry Laboratory Investigations. Research in Science Education. 43(5), 1763-1783.

Cohen, L., Manion, L. \& Morrison, K. (2000). Research methods in education, 5th edition, London: Routledge.

Cresswell, J. W. (2007). Qualitative inquiry \& research design: Choosing among five approaches (2nd ed.). US: Sage Publications.

D'Avanzo, C. (2013). Post-vision and change: Do we know how to change? CBE Life Sciences Education, 12(3), $373-382$.

Department of Education (DoE). (2002a). Revised National Curriculum Statement grade R - 9 (schools) Policy, Natural Science. Department of Education: Pretoria.

Department of Education (DoE). (2002b). Revised National Curriculum Statement grade R - 9 (schools) Policy, Overview - English, Department of Education: Pretoria.

Dikmenli M. (2009). Biology student teachers' ideas about purpose of laboratory work. Asia-Pacific Forum on Science Learning and Teaching, 10(2), 1-14.

Dodge, B. (1996). Teaching for active Learning. In http://edweb.sdsu.edu/people/bdodge/active /activelearning.html. Accessed $18^{\text {th }}$ August, 2013.

Ergin, O., Sahin-Pekmez, E. \& Ongel-Erdal, S. (2005). Kuramdan uygulamaya deney yoluyla fen ogretimi. Izmir, Dinazor Kitabevi.

Gee, B. \& Clackson, S. G. (1992). The origin of practical work in the English School science curriculum, School Science Review, 73, 79-83.

Gott, R. \& Duggan, S. (1996). Practical work: its role in the understanding of evidence in Science; School of Education, University of Durham, UK. International Journal of Science Education. 18(7), 791-806.

Gott, R. \& Mashiter, J. (1991). Practical work in Science: A task- based approach? pp. 177-179.

Hodson, D. (1992). Redefining and re-orientating practical work in school Science. The School Science review, 73(264), 655-675.

Hodson, D. (1996). A critical look at practical work in school Science. The School Science review, 71(156), 33-40.

Jacobs, S. (undated). Can Multimedia Bring the "Wow" to Science Learning? Vista University, Pretoria.

Johnstone A. H. \& Wham A. J. B. (1982) Demands of practical work, Education in Chemistry, 19, 71-73.

Kapenda, H. M., Kasanda, C. D., Lubben, F., Campbell, B. \& Kandjeo-Marenga, H. U. (2000). The Role of Practical Work in Science Teaching in Namibia, Paper presented at the SAARMSTE Conference in Maputo, Mozambique.

Klazky, R. L. (1984). Semantic factors in cognition. Hillsdale, N.J: Lawrance.

Kasanda, C. D., Lubben, F., Campbell, B., Kapenda, H. M., Kandjeo-Marenga, H. U. \& Gaoseb, N. (2003). Learner-Centred Teaching - The Rhetoric and Practice the Case of Namibia, pp.134. Paper presented at the 11th SAARMSTE conference in Waterford Kamhlaba.

Lawson, A. E. (2010). Basic inferences of scientific reasoning, argumentation, and discovery. Science Education, 94, 336- 364.

Maboyi. T. R. \& Dekkers, P. (2003). Science teachers purpose for doing practical work - Does professional Development make a Difference? University of the North, Turfloop, South Africa. pp. 722. Paper presented at the 11th SAARMSTE conference in Waterford Kamhlaba UWC, 2003

Miller, R. (2004). The role of the practical working the teaching and learning of Science, The University of York, Washington DC. pp. 2-6.

Reid, N. \& Shah, I. (2007). The role of laboratory work in university chemistry. Chemistry Education Research and Practice, 8(2), $172-185$.

Rubin, H. J. \& Rubin, I. S. (1995). Qualitative interviewing: The art of hearing data. Thousand Oaks, CA: Sage Publications.

Tafa, B. (2012). Laboratory activities and students practical performance: the case of practical organic chemistry. AJCE, 2(3).

Toplis, R. \& Allen, M. (2012). 'I do and I understand?' Practical work and laboratory use in United Kingdom schools. Eurasia Journal of Mathematics, Science \& Technology Education, 8(1), 3-9.

Woolfolk, A. E. (1998). Educational psychology. (7th ed.) Massachusetts: Allyn and Bacon. 